\title{
Erratum to: Hypoxemia as a model for high altitude and cardiovascular risk reduction
}

Friedrich C. Luft $^{1}$

Published online: 14 March 2016

(C) Springer-Verlag Berlin Heidelberg 2016

Erratum to: J Mol Med

DOI 10.1007/s00109-016-1390-7

There was an error in the last sentence of the figure legend. The correct sentence is: "Kang et al [11] suggest that chronic hypoxemia via HIF-1 $\alpha$ influences the anti-inflammatory IL-10 to protect against atherosclerosis in apoE -/- mice"

The online version of the original article can be found at http://dx.doi.org/ 10.1007/s00109-016-1390-7.

Friedrich C. Luft

luft@charite.de

Experimental and Clinical Research Center, Max-Delbrück Center and Charité Medical Faculty, Berlin, Germany 